\title{
Saber e Prática Docente na Transformação do Ensino Médico
}

\author{
Teaching Conceptions and Practice in the \\ Transformation of Medical Education
}

\author{
Ana Lúcia Pontes ${ }^{1}$ \\ Sergio Rego ${ }^{2}$ \\ Aluísio Gomes da Silva Junior ${ }^{3}$
}

PALAVRAS-CHAVE

- Educação Médica;

- Docentes;

- Ensino;

- Aprendizagem;

- Conhecimento

KEY-WORDS

- Education, Medical;

- Faculty;

- Teaching;

- Learning;

- Knowledge.

Recebido em: 24/05/2006

Reencaminhado em: 03/07/2006

Aprovado em: 10/07/2006

REVISTA BRASILEIRA DE EDUCAÇ̃̃o MÉDICA
${ }^{1}$ Laboratório de Atenção, Escola Politécnica de Saúde Joaquim Venâncio, Fundação Oswaldo Cruz, Rio de Janeiro, Brasil.

${ }^{2}$ Escola Nacional de Saúde Pública Sergio Arouca, Fundação Oswaldo Cruz, Rio de Janeiro, Brasil.

${ }^{3}$ Instituto de Saúde da Comunidade, Universidade Federal Fluminense, Rio de Janeiro, Brasil.

\begin{abstract}
RESUMO
Este estudo discute a concepção de ensino-aprendizagem dos preceptores da disciplina Trabalho de Campo Supervisionado II (TCS II) do curso de Medicina da Universidade Federal Fluminense, visando levantar elementos para uma reflexão sobre a prática docente no processo de transformação do ensino médico. A inserção precoce de estudantes nos serviços de Atenção Básica constitui uma estratégia freqüente nos novos cursos de Medicina. Procuramos levantar a discussão da relevância da epistemologia docente nestas práticas, e nosso referencial adotado foi o construtivismo. Observamos que os preceptores, freqüentemente, apresentam uma concepção empirista de ensino, na qual existe uma desarticulação entre teoria e prática, e passividade por parte do aluno. Porém, ao refletirem sobre a prática, apontam para uma proposta construtivista de ensino-aprendizagem, sendo que a estrutura do TCS II a favorece. A partir deste trabalho, apontamos a importância de conhecer os saberes e práticas dos professores como um ponto de partida para uma formação e reflexão crítica acerca do papel docente, para que se consolidem as transformações desejadas na escola médica.
\end{abstract}

The purpose of this study is to discuss the conception about the teaching/learning process of the teachers lecturing the discipline "Supervised Field Work II" of the medical course at the Federal University Fluminense. We aim to raise elements allowing for reflection about the teaching practice in the transformation of medical education. Early insertion of medical students into primary care services is a usual practice in the new medical courses. We discuss the relevance of the epistemological aspects of these practices on the basis of constructivism as a theoretical reference. The theoretical conception of the teachers about the teaching/learning process was frequently empiristic, characterized by disarticulation of theory and practice and a passive role of the student. When reflecting about their real practices however, the teachers showed a more constructivist approach to education, also with respect to a more active attitude of the student. This study aims to emphasize the importance of the teaching conceptions and practices of teachers for the new curriculum of the medical courses in order to advance in the transformation of medical education. 


\section{INTRODUÇÃO}

Desde a década de 1950, tem-se debatido a necessidade de mudar o modelo de formação médica, buscando-se valorizar a atenção básica e os determinantes sociais da saúde. Atualmente, encontramos nas novas diretrizes curriculares dos

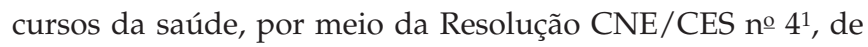
2001, um enfoque em habilidades e competências, que rompe com a tradicional estrutura de conteúdos disciplinares mínimos. A ênfase é dada a um médico generalista, que saiba integrar ações de promoção e prevenção à saúde com ações de recuperação e reabilitação, preconizando um enfoque integral do indivíduo e uma concepção ampla do processo saúdedoença.

Assim, os vários movimentos do campo da educação médica - como Integração Docente Assistencial, Projetos UNIa $^{a}$ Cinaem $^{b}$ (Comissão Interinstitucional para Avaliação do Ensino Médico), diretrizes curriculares - têm recomendado a inserção precoce dos estudantes de Medicina em serviços da Atenção Básica como proposta para mudar o perfil dos profissionais. Mas será que esse tipo de estratégia é suficiente para mudar a concepção e as práticas dos atores sobre o processo de ensino-aprendizagem?

Neste estudo, discutimos a relevância do saber docente na implementação de estratégias inovadoras no ensino médico. Assim, identificamos elementos que colaborem para a real transformação do ensino médico e a mudança do perfil do profissional formado.

\section{A TRANSFORMAÇÃO DO ENSINO E A EPISTEMOLOGIA DOCENTE}

Muitas prpostas de mudança têm sido debatidas, mas poucas escolas médicas, de fato, passaram por um processo de transformação da estrutura curricular. Freqüentemente, o que se observa nos processos de reforma curricular é a incorporação de novas disciplinas, uso de novos materiais didáticos ou incorporação de novas técnicas pedagógicas ${ }^{2}$. Desta maneira, mantém-se a ênfase num ensino baseado em transferência de conteúdos, no qual o aluno é passivo, os problemas são teóricos, e os saberes e práticas são fragmentados. Mesmo nas atividades práticas, nos modelos tradicionais, os alunos são apenas espectadores privilegiados da assistência, o

\footnotetext{
a A proposta UNI - "Uma nova iniciativa em educação nas profissões de saúde: união com a comunidade" - foi uma continuidade das experiências anteriores de Integração Docente Assistencial, iniciada na década de 1990.

${ }^{b}$ Em 1991, 11 entidades instituíram a Comissão Interinstitucional para Avaliação do Ensino Médico, que consistiu num processo para diagnóstico e transformação do ensino médico, em três fases.
}

que os incentiva a buscar adquirir a experiência clínica em estágios extracurriculares sem supervisão ${ }^{3}$.

Nesses processos tradicionais de reforma curricular, pode-se encontrar a discussão sobre o papel da escola médica ou o perfil do médico, mas raramente se discute a concepção de saúde, conhecimento ou educação.

Assim, gostaríamos de reforçar que:

Os currículos expressam o modo como uma instituição educacional se vê no mundo, ou seja, qual o seu papel, que relações ela deve estabelecer, quem são seus interlocutores, como se concebe o conhecimento (como ele é produzido, para que serve), como se concebe a educação, qual o melhor jeito de aprender, como a escola se organiza considerando os elementos anteriores, o papel (e o poder) que cada um tem dentro da escola. No caso de uma escola de medicina, o currículo também expressa a concepção que se tem sobre saúde, sobre o papel do médico na sociedade, sobre o médico que se quer formar etc. $^{2}$

Desta maneira, nos processos de reforma curricular temos uma disputa entre vários atores que defendem diferentes concepções de escola e práticas médicas e de ensino. Mas continuamos a afirmar que, para formar um profissional que atue segundo uma nova lógica, voltada para a humanização e integralidade do cuidado, necessitamos de um novo modelo de formação, talvez de um novo modelo pedagógico.

Entretanto, um questionamento se impõe: qual a relevância de discutir a concepção epistemológica dos docentes para refletir sobre uma prática de ensino-aprendizagem?

Entendemos que os referenciais e teorias servem como guia da prática educativa, pois acreditamos que a prática docente está sujeita a imprevistos, elementos inconscientes e externos que não são de controle do professor. Assim, para refletir sobre o que faz, o professor precisa recorrer a determinados referenciais que guiem, fundamentem e justifiquem sua atuação.

Ressaltamos, assim, o caráter instrumental das explicações teóricas, para interpretar, analisar e intervir na realidade. Os professores, portanto, necessitam de teorias sobre como se aprende e como se ensina. E cada professor, de acordo com sua bagagem e experiência, irá atribuir um sentido e um significado particular a essas teorias para torná-las significativas e funcionais em seu trabalho ${ }^{4}$.

Desta maneira, nos propomos, neste estudo, refletir sobre uma prática de ensino médico por meio da análise dos saberes docentes. Por isso, o objetivo deste estudo é analisar as concepções epistemológicas dos preceptores da disciplina 
Trabalho de Campo Supervisionado II do curso de Medicina da Universidade Federal Fluminense.

\section{TEORIAS DE ENSINO-APRENDIZAGEM}

Nossa questão é discutir a compreensão de docentes de Medicina sobre o que é o conhecimento, como se aprende, como se ensina e qual o papel do docente no processo de ensino-aprendizagem. Como subsídio para as reflexões que faremos com os resultados de uma pesquisa com docentes que atuam profissionalmente na preceptoria de atividades na rede básica de assistência, apresentaremos um breve panorama das diferentes concepções de conhecimento e aprendizagem. Apresentaremos inicialmente as teorias apriorista e empirista, seguidas, um pouco mais detalhadamente, da construtivista. A Figura 1 sintetiza a relação sujeito-objeto nas três abordagens teóricas.

FIGURA 1

Representação gráfica da relação sujeito-objeto de acordo com a concepção epistemológica.

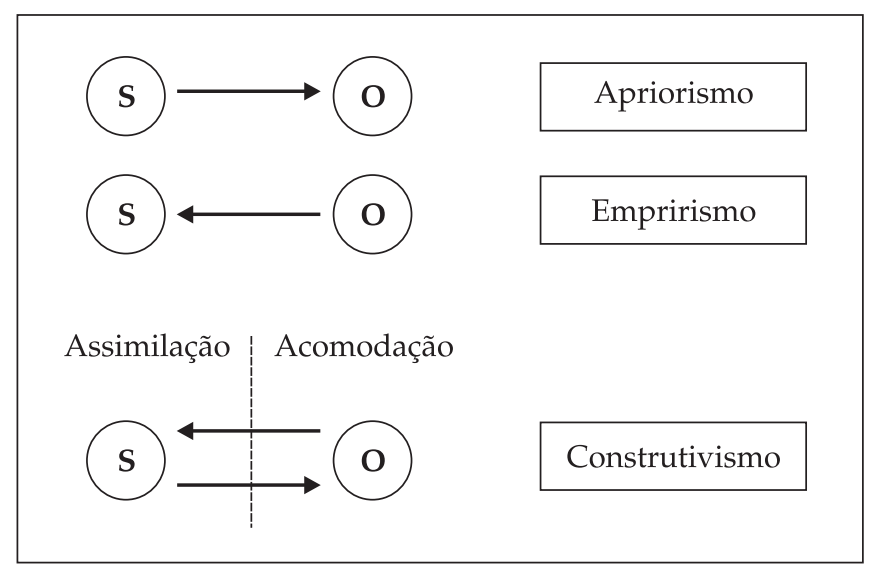

Fonte: Adaptado de Becker, $2003^{5}$.

Para os aprioristas, e nestes se incluem os inatistas, a origem do conhecimento está no próprio sujeito, ou seja, o conhecimento seria inato. Nesta concepção, o conhecimento é algo inerente ao sujeito, que precisa ser despertado. O raciocínio seria inato, e o ensino teria o papel de expandir o que já vem constituído na bagagem hereditária. Desta maneira, caberia ao professor estimular o aluno para que o conhecimento aflore. Como conseqüência deste tipo de concepção, observa-se que o ensino deixa de ser responsabilizado pelo êxito precário na aprendizagem discente ${ }^{6}$.

Numa concepção oposta, a dos empiristas, as bases do conhecimento estão na observação e percepção dos objetos. Segundo esta concepção, o aluno nada tem de conhecimento a priori, todo ele virá do meio externo ${ }^{7,5}$. Esta teoria foi subsidiada por muitos filósofos, para os quais o conhecimento é uma verdade no mundo que vai ser percebida pelos sentidos. Nada deve ser aceito sem antes ter passado pela experiência dos sentidos, das sensações. O conhecimento é algo que vem do objeto, e o sujeito é passivo, utilizando seus sentidos para absorver esta verdade do mundo do objeto. O homem é considerado uma espécie de tábula rasa, na qual são impressas, progressivamente, imagens e informações fornecidas pelo ambiente, cabendo a ele repeti-las ${ }^{8}$.

Esta epistemologia fundamenta práticas pedagógicas do tipo repetição ou reprodução. Este campo seria fértil para o autoritarismo e sua fundamentação na teoria e prática ${ }^{6}$. Nesta perspectiva, as experiências práticas de ensino-aprendizagem seriam um recurso sensorial por meio do qual se retira a teoria do objeto. A teoria seria algo que está no objeto. A ação do aluno durante a prática é extrair esta teoria da experiência. $\mathrm{O}$ papel do professor seria passar os conceitos para o aluno, e conhecer consiste em apreender uma verdade.

O construtivismo é uma abordagem que tem como um de seus principais teóricos Jean Piaget, que desenvolveu a teoria da epistemologia genética. Nas formulações desse autor, temos uma articulação das duas concepções apresentadas anteriormente. Segundo sua teoria, sujeito e objeto se constroem mutuamente na interação. Para Piaget ${ }^{9}$, o conhecimento nem é inerente ao sujeito (apriorismo), nem provém do meio externo (empirismo); o conhecimento principia na interação. Assim, o sujeito realiza ações para poder interpretar e internalizar o objeto nas suas estruturas cognitivas. Esse processo de transformação no mundo objetivo Piaget denominou assimilação. Por outro lado, o sujeito altera suas estruturas cognitivas para poder compreender o objeto, realiza uma transformação em si mesmo, denominada acomodação.

Assim, assimilação é ação transformadora do sujeito sobre o objeto. Acomodação é ação transformadora do sujeito sobre si mesmo. Nesses sucessivos processos de assimilação e acomodação, vai-se dando o processo de desenvolvimento cognitivo, segundo Piaget. Por ser uma teoria que pressupõe que o conhecimento não é dado, nem terminado, e que se constitui pela força da ação, denominou-se essa teoria de construtivismo. Essa construção, portanto, depende das condições do sujeito e do meio $7,5,9$.

Considera-se que o sujeito é construído por meio de sua própria ação, no espaço e no tempo, sobre o meio social, econômico e cultural. Desta maneira, o sujeito é considerado um sujeito histórico, cultural, social, político ${ }^{6}$. Para Piaget, as estruturas não estão pré-formadas no sujeito, este as constrói na medida das necessidades e das situações. A experiência não é uma recepção passiva, é um processo ativo. 
Assim, se Piaget fundamentou consistentemente a dimensão construtivista do aprendizado, Vygotsky caracterizou melhor a dimensão interacionista ${ }^{10}$. Vygotsky deu grande importância à relação e interação com outras pessoas durante o processo de aprendizagem. Para melhor entendermos o papel da interferência do outro na aprendizagem, nos apropriaremos do conceito de Zona de Desenvolvimento Proximal (ZDP) desse autor, definida como "a distância entre o nível de resolução de uma tarefa que uma pessoa pode alcançar atuando independentemente e o nível que pode alcançar com a ajuda de um colega mais competente ou experiente nessa tarefa"11. Assim, é na ZDP que se pode, graças aos suportes e à ajuda de outros, desencadear o processo de construção, modificação, enriquecimento e diversificação dos esquemas de conhecimento. Espera-se que o que a pessoa realiza com a ajuda de outras pessoas poderá, posteriormente, realizar de maneira autônoma.

Alguns pontos necessitam ser enfatizados em relação à ZDP. Primeiro, ela não tem efeitos lineares nem automáticos sobre os alunos, eles têm que ser conectados ao processo de aprendizagem dos alunos. Segundo, o ensino não pode proporcionar ajudas homogêneas e idênticas para todos os casos e alunos. Por último, esta ajuda deve ser ajustada na dimensão temporal do processo de aprendizagem do aluno, para cada momento.

Os trabalhos de Vygotsky enfatizam o papel da interação social ao longo do desenvolvimento - o processo individual de construção do conhecimento teria sua raiz na sociedade e na cultura. Desta maneira, para esse autor, "a aprendizagem é concebida do exterior do sujeito para o interiorc (fruto das interações com o mundo) por meio de um processo de internalização das ações sociais, transformando-as em ações intrapessoais (internalizando o conhecimento adquirido)"12.

Acreditamos que os trabalhos de Piaget e Vygotsky não entram em contradição, mas ressaltam diferentes aspectos do processo de aprendizagem na concepção construtivistad. $\mathrm{Na}$ verdade, utilizando os trabalhos desses dois autores, adotamos a idéia de que "no homem, o aspecto biológico encontrase enredado o tempo todo no processo sócio-histórico, representado pelas transformações das expressões culturais" ${ }^{\prime 13}$.

\footnotetext{
${ }^{c}$ Este é um ponto em que os trabalhos de Piaget e Vygotsky entram em conflito, mas adotamos a perspectiva de Vygotsky como um alerta de que os conteúdos, prática e habitus aprendidos são social e historicamente contextualizados. Para detalhes sobre a confrontação dos trabalhos desses autores, ver Leite ${ }^{10}$.

${ }^{d}$ De fato, Piaget e Vygotsky partiram de pressupostos teóricos e formações muito distintos, mas, por causa destas mesmas razões, seus trabalhos entram em conflito mas não se aniquilam, podendo ser usados complementarmente.
}

Desta maneira, o professor adquire uma nova função: propiciar situações nas quais o aluno possa construir o conhecimento. $\mathrm{O}$ construtivismo preconiza que o aluno passe pelo processo de construção do conhecimento por meio da interação entre sujeito e objeto. E interação significa que o conhecimento se origina numa zona intermediária entre sujeito e objeto, ou seja, não se origina nem no sujeito nem no objeto. O mundo do objeto provocaria perturbações e desequilíbrios nas estruturas do sujeito, e este, por meio das ações de assimilação e acomodação, modificaria suas estruturas, produzindo conhecimento. A cada nova interação este processo continuaria, daí o termo construtivismo.

O papel do professor seria trabalhar e desafiar o aluno para construir o conhecimento para além das aparências, das percepções cotidianas e ações práticas. O ensino, então, é entendido como uma ajuda necessária ao processo de aprendizagem. E é entendido como ajuda, pois não deve substituir a atividade mental construtiva do aluno ${ }^{14}$. Desta maneira, o ensino como ajuda tem algumas características: a) deve levar em conta os esquemas iniciais de conhecimento dos alunos e tomar como ponto de partida os significados e os sentidos que os alunos tenham sobre o conteúdo; b) deve provocar desafios que estimulem o questionamento desses significados e sentidos, favorecendo modificações, ou seja, apontando para o que o aluno não conhece. Assim, o ensino dependerá do ponto de partida do aluno e se dará por meio de desafios que o aluno enfrentará dentro de suas possibilidades e dos apoios e instrumentos oferecidos pelo professor.

\section{O CONTEXTO LOCAL DO ESTUDO}

Nosso estudo tomou como objeto uma disciplina do curso de Medicina da Universidade Federal Fluminense, implantada na última reforma curricular. A construção da proposta foi finalizada em 1992 e ela foi implantada em 1994. Esta reforma curricular procurou privilegiar a atuação precoce dos alunos em rede hierarquizada de serviços e as práticas comunitárias, tendo ampliado a participação dos alunos nas atividades práticas e estendido o Internato para dois anos.

A inserção dos alunos na rede básica de saúde se dá por meio do Trabalho de Campo Supervisionado (TCS) do Programa Prático Conceitual (PPC). O objetivo do TCS seria "desenvolver no aluno, a partir de uma realidade imediata, e no interior do SUS, o espírito crítico, a criatividade, a capacidade de discernimento, a capacidade de planejamento e ação (...) e o compromisso ético para com a população"15.

O TCS se desenvolve durante os quatro primeiros anos do curso, sendo formados grupos de oito a dez alunos, supervisionados por um docente ou tutor. No segundo ano (TCS 
II), busca-se identificar o perfil epidemiológico (morbidade e mortalidade), construir análises e propostas de funcionamento das unidades de saúde e analisar o impacto das ações programadas sobre as condições locais diagnosticadas. É nesse período que todos os alunos são inseridos nos serviços de saúde, que podem ser uma Unidade de Saúde, Policlínica ou módulo do Programa Médico de Família. Durante o TCS II, os alunos desenvolvem dois tipos de atividades: vão observar e progressivamente se inserir no processo de trabalho na unidade e vão desenvolver um projeto de estudo específico a partir de uma demanda do serviço. Em nosso estudo, entrevistamos os preceptores deste momento de TCS.

Esta disciplina representa um dos aspectos mais interessantes do curso de Medicina da UFF, que é a inserção do aluno, desde o primeiro período, em atividades práticas, para além do Hospital Universitário ${ }^{16}$. Entretanto, a plena implementação do TCS constitui, ainda hoje, o principal desafio do novo currículo. Como dificuldades para a inserção dos alunos na rede de serviços, temos o número reduzido de docentes interessados em participar do TCS, devido ao deslocamento físico, e a deficiência na formação docente e dos demais profissionais para atuarem segundo os novos métodos de ensino-aprendizagem e referenciais de modelos tecnoassistenciais, como a integralidade e a interdisciplinaridade ${ }^{17,18}$.

Assim, nos parece que a caracterização dos atores envolvidos na implementação do TCS e suas representações acerca desse processo de ensino-aprendizagem permitiriam repensar seus objetivos, estratégias e resultados.

\section{O PERCURSO METODOLÓGICO}

Esta pesquisa obedeceu aos preceitos da Resolução 196/ 96 do Conselho Nacional de Saúde, tendo sido avaliada e aprovada primeiramente pelo Comitê de Ética em Pesquisa da ENSP/ Fiocruz, em agosto de 2004.

O método da pesquisa baseou-se na observação participante e na realização de entrevistas com roteiro semi-estruturado. A realização de entrevistas foi considerada uma estratégia metodológica pertinente, pois permite compreender atitudes, valores e opiniões dos sujeitos ${ }^{19}$. Então, definimos como nosso universo de entrevistados todos os preceptores de TCS II. Assim, de setembro a outubro de 2004, entrevistamos oito dos dez preceptores da disciplina de Trabalho de Campo Supervisionado II, a fim de entender as concepções acerca do processo de ensino-aprendizagem. Dois docentes não tiveram disponibilidade de tempo para serem entrevistados, mas esta perda foi avaliada como não sendo prejudicial ao trabalho.

O roteiro semi-estruturado serviu como um condutor da conversa, tendo sido permitido ao entrevistado falar livre- mente sobre os tópicos que lhe parecessem mais relevantes. Desta maneira, as entrevistas duraram entre 20 minutos e 1 h30 minutos. Antes de cada entrevista, os participantes leram o "Termo de Consentimento Livre e Esclarecido", o procedimento foi explicado, e, após concordância com o mesmo, deu-se início à entrevista, que foi gravada.

Em relação ao tratamento analítico dos dados, consideramos que o mais apropriado aos nossos objetivos era a análise de conteúdo. Realizamos uma análise temática, que procura descrever os núcleos de sentido referentes a um objeto visado ${ }^{20}$ - em nosso caso, a concepção de processo de ensinoaprendizagem. Nossa análise procurou relacionar a fala dos entrevistados com três concepções de processo de ensinoaprendizagem: empirismo, apriorismo e construtivismo.

\section{A FALA DOS PRECEPTORES}

Na análise deste trabalho, não pretendemos tão-somente classificar os docentes como empiristas, aprioristas ou construtivistas, pois entendemos que atribuir um rótulo em um discurso representaria uma contribuição limitada às reflexões sobre o processo de ensino-aprendizagem. Assim, optamos por identificar a maior quantidade de elementos que nos permitam uma reflexão mais ampla sobre a prática docente. E, principalmente, considerando que esses preceptores fazem parte de uma disciplina que pretende ser inovadora no campo da saúde, apontar alguns aspectos que colaborem para a reflexão sobre o movimento de mudança do ensino médico.

Assim, quando inquiridos sobre o que seria aprender, um aspecto freqüente foi a distinção entre aprender e apreender, expressa nas falas a seguir:

Você leu num livro, você apreendeu, você registrou, você guardou um montão de informações, mas, em determinados momentos, você vai aprender. Você vai colocar o que você apreendeu para o aprendizado da pessoa. Entende? Transformar o que você apreendeu em realizar, pôr em prática isso. (D4)

Segundo o Novo Dicionário Aurélio da Língua Portuguesa 21 , apreender significa: "segurar, pegar, agarrar, prender; ou assimilar mentalmente; entender, compreender: Apreende rapidamente tudo o que lhe ensinam". Partindo desse sentido, parece-nos que no processo de ensino-aprendizagem existiria uma dicotomia entre teoria e prática: a prática seria uma forma de melhorar a apreensão (memorização) da teoria e/ou de testar a apreensão da teoria, ao passo que a teoria seria um conteúdo ideal e imutável a ser transmitido pelo professor, dissociado da prática. 
Por outro lado, Freire 22 assinalou que somos capazes de aprender, pois temos a "habilidade de apreender a substantividade do objeto aprendido", a partir da qual podemos reconstruir, mudar o mundo. O sentido de "apreender" de Freire é o de ser capaz de realizar uma ação de segundo grau, ou seja, de buscar e compreender os mecanismos íntimos da ação, o que permitiria ser capaz de gerar esquemas generalizáveis e lidar com situações diversas, e criar a partir do aprendido. Assim, o "apreender" do entrevistado parece estar mais relacionado com a memorização do que com o sentido de compreensão de Freire.

Ou seja, a perspectiva da prática numa concepção construtivista é mais ampla do que simplesmente a capacidade de colocar em prática o que foi ensinado, como alguns de nossos entrevistados apontaram. Ressaltamos que, a partir desse ponto, corre-se o risco de limitar a prática a um saber-fazer, simplesmente, e não ligá-la à construção permanente do conhecimento a partir da prática, de modo a formar profissionais reflexivos. Senão, pode-se novamente atribuir a produção teórica aos acadêmicos, e caberia aos profissionais somente aplicar as teorias. Pelo contrário, pretendemos que os estudantes e os docentes incorporem a reflexão e a construção do conhecimento a partir também de suas práticas, em seu habitus profissional.

A relação com a realidade e a prática foi expressa por alguns preceptores como sendo: "Você está no mundo absorvendo várias informações" (D1), e conseqüentemente, devido ao termo "absorvendo", nos questionamos se a concepção de processo de ensino-aprendizagem de fundo não seria empirista, pois sua característica principal no ensino é considerar o aluno uma tábula rasa, na qual o professor irá imprimir as informações; o aluno é passivo. Em outro momento também percebemos esta característica:

Agora o subjetivo também você tem possibilidade de estimular através das sensações, das emoções. (D2)

O sentido de "estímulo" apresentado não fica claro. Parece-nos que neste caso os sentidos são passivos, reforçando a característica empirista; ou pode-se dizer que se aponta também para um apriorismo, no sentido de despertar no aluno o conhecimento. Por outro lado, de alguma forma esta fala aponta para o pólo do sujeito no processo de ensino-aprendizagem; parece-nos que existe um reconhecimento de que o sujeito construiu algo previamente - que seriam as estruturas segundo Piaget. Existe, por parte destes preceptores, um reconhecimento de que o sujeito-aluno influencia o processo de ensino-aprendizagem:

tanto que é muito interessante porque nenhum semestre ele é igualzinho ao outro. Nem dá até porque os alunos não são iguais também. (D2)
Assim, apontando que o aprendizado depende do sujeito: Eu acho é você querer aprender. (D6)

tem o predicado da disponibilidade de se dispor a aprender. Porque é impossível você transmitir ou o conhecimento chegar a quem não esteja disposto a receber aquele tipo de informação. (D3)

Entretanto, novamente, percebemos que existe na fala dos preceptores uma concepção de fundo empirista, na qual a participação do sujeito é a disponibilidade em receber informações, e a vontade existe a priori no sujeito. Ou, até mesmo, ficamos com a impressão de que se atribui uma grande importância a uma bagagem fixa de cada aluno, e que, dependendo da mesma, pode-se despertar ou não o conhecimento, o que seria uma tese apriorista. No construtivismo, a vontade ou disponibilidade de aprender é entendida como em construção e depende das estruturas anteriores do sujeito. Este vai ter interesse em aprender algo que suas estruturas prévias reconhecem.

Em nossa interpretação, os preceptores limitam a participação do aluno à questão da vontade do aprendizado, não deixando claro como eles lidam em suas práticas educativas com estas estruturas prévias do aluno. Seriam estas um substrato para o aprendizado?

Um dos pontos fundamentais do construtivismo é que a aprendizagem se torna mais significativa quanto mais relacionada estiver com os conhecimentos prévios do aluno e quanto maiores forem as relações com o objetivo da aprendizagem, sendo que este deveria ser o ponto de partida do processo de ensino. Encontramos alguns preceptores que apontam para esta perspectiva mais dinâmica de aprendizado:

Vivendo e dentro da vivência você tem leituras, você tem interlocuções, você tem congressos e você tem surras (...) É a experiência (...) ensaio e erro. (D5)

Este preceptor conceitua o termo experiência como algo em construção constante, em que os erros seriam substrato para o aprendizado, e as leituras seriam subsídio da vivência. Encontramos outra elaboração interessante de um preceptor, que identificamos como construtivista:

Como se aprende? Seria assim, seria eu vivendo e em cima da vivência refletindo sobre essa vivência e essa minha reflexão, óbvio, alimentada por um conjunto de pessoas que já pensou sobre isso, já escreveu sobre isso, já está discutindo isso e eu fazer essa relação entre essas coisas. E ter a possibilidade de olhar para minha experiência de uma outra forma. (D8) 
Gostaria de enfatizar o final esta fala: "possibilidade de olhar para minha experiência de uma outra forma". Ele caracteriza muito bem a perspectiva de que o processo de conhecimento é inacabado e contínuo: cada "novo olhar" sobre um objeto ou experiência irá resultar num novo conhecimento e, assim, num processo de superação constante. Isto nos remete à "consciência de inacabamento" de Paulo Freire ${ }^{23}$, que seria o núcleo fundamental em que se sustenta a educação. Porque se percebe como um ser inacabado, o homem deve ser sujeito de sua própria educação, em comunhão com outros que se percebem inacabados. Assim, a educação seria uma "busca permanente de si mesmo (...) feita com outros seres que também procuram ser mais" 23 .

E, de certa maneira, indicando a importância do diálogo no processo de aprendizado, algumas falas reforçam a importância de uma comunicação salutar entre professor e aluno, que permita a crítica e que não seja autoritária. O diálogo ganha uma dimensão muito importante no construtivismo, pois a fala é sempre uma ação de segundo grau, ou seja, ação sobre alguma ação anterior. Por meio da fala constrói-se o conhecimento como estrutura e como conteúdo ${ }^{6}$. E o diálogo com o professor e com os colegas permite o contraste entre diversos pontos de vista, a explicitação da própria opinião, sendo um exercício de prática de termos científicos, entre outros aspectos ${ }^{14}$.

Não que eu seja o dono da informação. Mas porque eu tenho o conhecimento e a partir disso, você disponibilizar esse conhecimento não de uma forma autoritária, mas de uma forma compartilhada com aquele outro que não tenha esse conhecimento. Mas deixando aberta ao outro a possibilidade de criticar você e trazer novas informações que muitas das vezes você não sabe. (D3)

A palavra "disponibilizar", de certa forma, aponta para uma concepção empirista subjacente, para o "ensino bancário", criticado por Freire ${ }^{22}$, o que em alguns casos ficou claro como sendo a maneira pela qual o preceptor entende o processo de ensino-aprendizagem, como no caso a seguir:

Acho que ensinar é transmitir a sua experiência, entendeu? O seu conhecimento. Eu vou passando adiante. E para isso a didática que você tem que ter, a psicologia que você tem que ter é que você tem que saber fazer. Porque não adianta você ter um conhecimento muito grande dentro da sua cabeça e não saber passar. (D5)

Transmitir o que a gente aprendeu. (D7)

Estes preceptores nos lembram a concepção tecnicista de ensino, na qual a didática é entendida como a incorporação de tecnologias que facilitem a transmissão de conhecimento. Freqüentemente, a percepção de formação docente recai nessa perspectiva, que não transforma as práticas educativas. Esses preceptores nos mostraram claramente como na concepção empirista a teoria é uma verdade que se encontra na realidade, e o papel do docente seria apontar esta verdade, a teoria.

Depois a gente vai para outra salinha que tem lá dentro, que é a sala dos médicos, aí eu chamo todo mundo lá para dentro. Olha, é isso, isso, isso, isso, isso, isso. Aí passo a teoria. A teoria, minha. Aí peço para eles, agora, vocês vão ler quando chegar em casa. Tem o capítulo do... Eu dou lá algumas referências bibliográficas que tem, tá? E vocês vão ler. Se vocês tiverem alguma dúvida vocês tragam para cá na próxima aula que a gente conversa. (D5)

O diálogo entre professor e alunos se refere a uma verdade dada e construída, que vai ser identificada na realidade. A teoria não é uma construção, é uma verdade a ser percebida na realidade. Mas encontramos preceptores que, quando questionados sobre o que seria ensinar, mantêm uma postura construtivista - a prática como objeto de reflexão a partir do qual se constrói a teoria.

E querer trabalhar a partir da realidade do que as pessoas estão vivendo, aquele conjunto de questões que estão colocadas por disciplina. (D8)

É interessante notar que alguns preceptores desenvolveram melhor suas idéias quando questionamos sobre o aprender e outros sobre o ensinar. Entretanto, foi curioso observar que, quando questionamos os preceptores sobre o papel do professor e do aluno no processo de ensino-aprendizagem, vários depoimentos foram contraditórios com a visão empirista predominante inicialmente, e mais próximos de uma concepção que enfatiza a interação entre professor e aluno.

Eu acho que é mais estimular. E aí bem... A gente remete logo à questão da pesquisa como sendo... Não é? Um instrumento de ensino-aprendizagem muito importante (...) Então, essa palavra-chave da problematização, ela é importante (...) quando eu falei do início aquela coisa de compartilhar um pouco esse processo de ensino-aprendizagem. (D1)

Porém, na fala deste preceptor, um pouco mais adiante, vemos que esta construção está mais relacionada com a grande quantidade de conhecimento que está sendo construída e com a velocidade de produção do conhecimento; o professor sairia prejudicado se tivesse a "presunção" de saber tudo, já que com a internet o aluno tem um acesso muito fácil e rápido 
ao conhecimento. De qualquer maneira, diante dessa realidade, o papel do professor seria estimular o aluno a buscar esse conhecimento.

Eu percebo o papel do professor um papel de sensibilizador e facilitador, entendeu, que ele pode até ter conteúdos diferenciados, mas ele é um facilitador. Porque o conteúdo, o aluno, se ele estiver sensibilizado, ele pode buscar. (D2) É você saber estudar junto com os alunos. Entendeu? Eu acho que isso é muito importante porque o aluno traz muita coisa para a gente. (D6)

A ênfase na construção do conhecimento talvez fique mais clara na fala a seguir, que reforça não só esta busca do conhecimento, mas, principalmente, a discussão do processo de produção do conhecimento. Como Becker6 enfatizou, Piaget esclarece que mais importante que o conteúdo é a estrutura, que o aluno incorpore os mecanismos de produção do conhecimento.

Ser uma pessoa que estimule a busca pelo aprendizado, não é? E uma pessoa que compartilhe dessa construção do aprendizado, não é? Seria muito bom se todos os alunos tivessem possibilidade de participar desse momento, mas também da construção do conhecimento. (D8)

Também encontramos a associação do papel do professor a um intermediador entre a experiência prática e a teoria. Novamente, segundo uma concepção empirista em que a teoria é retirada da prática, que seria somente um recurso sensorial.

Eu acho que é ser ponte, tá? Entre a matéria científica que eu li e a experiência deles. (D5)

Assim, o docente seria responsável por reforçar que as teorias se encontram na realidade:

O que eu preciso fazer é propiciar ao aluno que teve aquele conhecimento aplicá-lo no trabalho de campo. Aí eu vou estar produzindo um ensinamento para ele. (D3)

Um dos preceptores apontou uma questão importante: a da formação que tiveram, predominantemente numa perspectiva tradicional e que também é o modelo que prevalece na faculdade de Medicina. Romper com este modelo é uma dificuldade para docentes e alunos.

\section{CONSIDERAÇÕES FINAIS}

Nosso estudo se insere numa discussão político-conceitual do ensino médico, pois diferentes concepções do aprender e do ensinar geram diferentes currículos. Esta reflexão é pou- co freqüente nas escolas médicas e é para ela que pretendemos contribuir com este estudo.

Isso se torna relevante porque, em geral, nos processos de reforma curricular na Medicina, tem-se partido do pressuposto de que, inserindo os alunos num novo espaço de prática, necessariamente estes se sensibilizarão para uma nova postura como médicos. Esta percepção de que o aprendizado é passivo por parte do aluno, que basta expô-lo a um novo ambiente que ele irá absorver é um caminho que pode levar ao insucesso dessas propostas inovadoras. No processo de aprendizagem, o sujeito é ativo, e o papel do professor é explicitar as práticas, objetivos e relações deste aprendizado para sua formação e estimular uma reflexão sobre esta nova prática. Se não, estaremos fadados a mudar pouco o perfil do profissional médico formado.

No desenvolvimento do nosso estudo, percebemos, como Becker6, um estranhamento, e às vezes um constrangimento, dos professores ao serem interrogados sobre suas concepções de processo de ensino-aprendizagem. Assim, não nos surpreendemos quando constatamos um forte caráter empirista na fala dos preceptores ao explicarem suas concepções de processo de ensino-aprendizagem. A prática é identificada freqüentemente como fonte da qual se retira ou aplica a teoria. Percebemos poucas falas que identificaram a reflexão sobre a prática como uma estratégia de aprendizado. Acreditamos que, sem uma reflexão profunda sobre esta relação entre teoria e prática, corre-se o risco de limitar a prática educativa no TCS a um simples saber-fazer, desperdiçando este rico material da prática como objeto de construção do conhecimento.

Por outro lado, também sabemos que os saberes docentes são fundamentais na produção do próprio saber-fazer docente e que, sem uma teoria que dê sentido às práticas, estas não se transformam. Assim, a partir dos saberes pedagógicos reais dos sujeitos de nossa pesquisa, que vão refletir sobre os problemas e experiências da prática, talvez se possa constituir um princípio da formação inicial e contínua dos docentes, o que é de extrema importância.

Na formação permanente dos professores, o momento fundamental é o da reflexão crítica sobre a prática. É pensando criticamente a prática de hoje ou de ontem que se pode melhorar a próxima prática. O próprio discurso teórico, necessário à reflexão crítica, tem de ser de tal modo concreto que quase se confunda com a prática. O seu "distanciamento" epistemológico da prática enquanto objeto de sua análise deve dela "aproximá-lo" ao máximo. 22

Considerando que, no momento da ação, o professor tem pouco tempo para refletir, pode-se encontrar na relei- 
tura da experiência, numa reflexão retrospectiva, o incentivo a uma nova leitura da experiência, que seria um fator de mudança, de reorganização de esquemas ou levaria a um conflito cognitivo encontrado na possível contradição entre as decisões tomadas em sala de aula e uma teoria, norma ou outra experiência ${ }^{24}$. E esta reflexão poderia ser alimentada por paradigmas interpretativos, teorias que seriam chaves de interpretação do que se passa numa sala de aula, que talvez pudessem constituir uma formação básica docente.

As transformações no ensino somente ocorrerão se os professores ampliarem sua consciência a respeito dos contextos históricos, sociais, culturais, organizacionais de sua própria prática educativa, tanto a da sala de aula quanto num sentido mais amplo. E a mudança do perfil dos médicos depende dessa transformação.

\section{AGRADECIMENTOS}

Gostaríamos de agradecer as contribuições de Ivi Tavares Castillero, Thiago Inocêncio Constancio, Daniele Minelli e Thomaz Canedo de Magalhães Filho.

Financiamento: esta pesquisa recebeu auxílio do Promed.

\section{REFERÊNCIAS}

1. Brasil. Resolução CNE/CES no.04/2001. Diretrizes Curriculares Nacionais do Curso de Graduação em Medicina. Diário Oficial da União, Brasília, 9 de Novembro de 2001, seção 1. p.38.

2. Feuerwerker L. Além do discurso de mudança na educação médica: processos e resultados. São Paulo, Londrina, Rio de Janeiro: HUCITEC, Rede UNIDA, Associação Brasileira de Educação Médica; 2002.

3. Rego S. A prática na formação médica - o estágio extracurricular em questão. [Dissertação] Instituto de Medicina Social, Universidade do Estado do Rio de Janeiro; 1994.

4. Solé I, Coll C. Os professores e a concepção construtivista. In: Coll C et al. (orgs).O Construtivismo na sala de aula. São Paulo: Ática; 2003.

5. Becker F. A origem do conhecimento e a aprendizagem escolar. Porto Alegre (RS): Artmed; 2003.

6. Becker F. A epistemologia do professor: o cotidiano da escola. Petrópolis (RJ): Vozes; 1993.

7. Becker F. O que é Construtivismo? São Paulo: FDE; 1994. p.87-92. Disponível em: http:// www.crmariocovas.sp.gov.br/pdf/ideias_20_pm87093_c.pdf Acessado em Julho de 2004. (Série Idéias, 20)
8. Mizukami MGN. Ensino: abordagens do processo. São Paulo: EPU; 1986.

9. Piaget J.O nascimento da inteligência na criança. Rio de Janeiro: Zahar; 1970.

10. Leite LB. As dimensões interacionsita e construtivista em Vygotsky e Piaget. Cadernos CEDES. 1991; (24).

11. Onrubia J. Ensinar: criar zonas de desenvolvimento proximal e nelas intervir. In: Coll $\mathrm{C}$ et al. (orgs). $\mathrm{O}$ Construtivismo na sala de aula. São Paulo: Ática; 2003.

12. Carvalho MAP. Análise de um ambiente construtivista de aprendizagem à distância: estudo da interatividade, da cooperação e da autonomia no Curso de Gestão descentralizada de Recursos Humanos em Saúde. [Dissertação]. Universidade Federal do Rio de Janeiro, Núcleo de Tecnologia Educacional para a Saúde, Rio de Janeiro, 2000.

13. Aranha MLA. Filosofia da Educação. São Paulo: Moderna; 1996.

14. Onrubia J. Ensinar: criar zonas de desenvolvimento proximal e nelas intervir. In: Coll C et al. (orgs).O Construtivismo na sala de aula. São Paulo: Ática, 2003.

15. Universidade Federal Fluminense. Currículo Pleno do Curso de Medicina da UFF. Niterói (RJ): UFF; 1992.

16. Koifman L. O processo de reformulação curricular de duas faculdades de medicina no Brasil e na Argentina: uma abordagem comparativa. Interface. 2003-2004; 8(14): 113-33.

17. Koifman L. A Reformulação do curso de medicina da Universidade Federal Fluminense. Revista do Centro de Ciências Médicas. 1998; 2(2).

18. Silva Júnior A et al. As experiências de articulação universidade-serviço-sociedade em Niterói-RJ. Divulgação em Saúde para Debate. 1996; (12):51-55.

19. Minayo MCS. O desafio do conhecimento: pesquisa qualitativa em Saúde. São Paulo, Rio de Janeiro: HUCITEC, ABRASCO; 1999.

20. Bardin L. Análise de conteúdo. São Paulo: Martins Fontes; 1979.

21. Holanda AB. Novo Dicionário Aurélio da Língua Portuguesa. São Paulo: Ática; 1989.

22. Freire P. Pedagogia da Autonomia. São Paulo: Paz e Terra; 1996.

23. Freire P. Educação e mudança. Rio de Janeiro: Paz e Terra; 1997.

24. Perrenoud P. Práticas pedagógicas, profissão docente e formação: perspectivas sociológicas. Lisboa: Publicação Dom Quixote/ Instituto de Inovação educacional; 1993. p.19-51. 


\section{Conflito de Interesses}

Ana Lúcia de M. Pontes era na ocasião da realização de pesquisa de campo, médica residente do Instituto de Saúde de Comunidade da Universidade Federal Fluminense

Aluísio Gomes da Silva Junior é professor do Instituto de Saúde da Comunidade da UFF

Sergio Rego não tem conflitos de interesse.

\section{Endereço para Correspondência}

Rua Gago Coutinho, 31 / cobertura CEP: 22221-070 - Laranjeiras - RJ

E-mail: analupontes@fiocruz.br 